\title{
Height and weight gain after total correction of Fallot's tetralogy
}

\author{
R. E. PAGE ${ }^{1}$, P. B. DEVERALL, D. A. WATSON, AND O. SCOTT \\ From the Cardio-Thoracic Unit, Killingbeck Hospital, York Road, Leeds
}

SUMMARY In a consecutive series of 100 cases of Fallot's tetralogy undergoing total correction, the mean birthweight was found to be just below the 50th centile. Blalock-Taussig or Waterston shunts were performed in 45 patients. Before their shunt operations a significant number of patients had become retarded in height and weight development but after the shunt operations many patients showed accelerated height and weight gain. Of the 73 patients followed up 2 years after correction, 23 had experienced accelerated development in both weight and height, but 11 patients remained on or below the 3rd centile for weight and height. In terms of the age at shunting, the oxygen saturation immediately before total correction, the age at total correction, the number of ventriculotomy patch repairs, and the post-correction ventricular pressure ratios, no significant difference could be detected between those 23 patients who had undergone accelerated development and those 11 who had remained retarded. More shunts, particularly of the Waterston type, were performed in the retarded group.

Growth retardation in infants suffering from congenital heart disease had been recognised for many years (Mazur, 1959; Schlange, 1962; Naeye, 1967). The extent of retardation is related to the type of anatomical lesion (Robinson and Bayer, 1969). Surgical correction with restoration of a functionally normal circulation can improve the general wellbeing of the patients and, in some anomalies, operation has been followed by an acceleration in growth (Adams and Forsyth, 1951; Mehrizi and Drash, 1962; Feldt et al., 1969). The aim of this paper was to analyse the growth patterns before and after surgical correction of Fallot's tetralogy (Fallot, 1888).

\section{Subjects and methods}

Between 1963 and 1974, 100 children, all below the age of 16 years, underwent total correction of Fallot's tetralogy. In each case a preoperative diagnosis was established on clinical grounds and by cardiac catheterisation. Forty-five of the patients underwent either a Waterston (1962) or BlalockTaussig (1945) shunt. Patients with additional medical conditions likely to affect growth, for

'Present address: Department of Plastic Surgery, St. James's Hospital, Beckett Street, Leeds 9

Received for publication 7 July 1977 example, diabetes mellitus, were excluded from the study. All patients were reviewed to make an assessment of clinical and developmental progress. The following were recorded: (a) birthweight; (b) age, height, and weight immediately before a shunt operation; (c) age, height, and weight immediately before total correction; (d) age, height, and weight two years after total correction. No attempt was made to obtain information of birth length since it has little significance in the neonatal period and is difficult to measure accurately.

To permit comparison between individuals of varying ages and also to monitor growth progress after shunt and then total correction procedures, it $\frac{D}{0}$ was necessary to convert all absolute values of height and weight to centiles using charts prepared by $N$ Tanner et al. (1966). By comparing preoperative $N$ centile ratings with postoperative values, it was pos- N sible to assess in each case whether there had been $\omega$ an acceleration in development. In absolute terms of height and weight gain, small jumps in the lower $\stackrel{0}{=}$ centile ranges are equivalent to larger jumps in the higher ranges. For example, the difference between the 3rd and 10th centile for height in a 10-year-old ${ }^{\circ}$ girl is $4 \mathrm{~cm}$; the difference between the 25th and $\underset{\mathbb{D}}{ }$ 50 th centile for a girl of the same age is only $5 \frac{\rho}{\mathbb{Q}}$ $\mathrm{cm}$. In order to make realistic comparisons patients $\frac{\varrho}{\sigma}$ were allocated to the appropriate centile groups as follows: below the 3rd, 3rd to 9th, 10th to 24th, 25 th to 49 th, 50 th to 74 th, 75 th to 89 th, 90 th to 

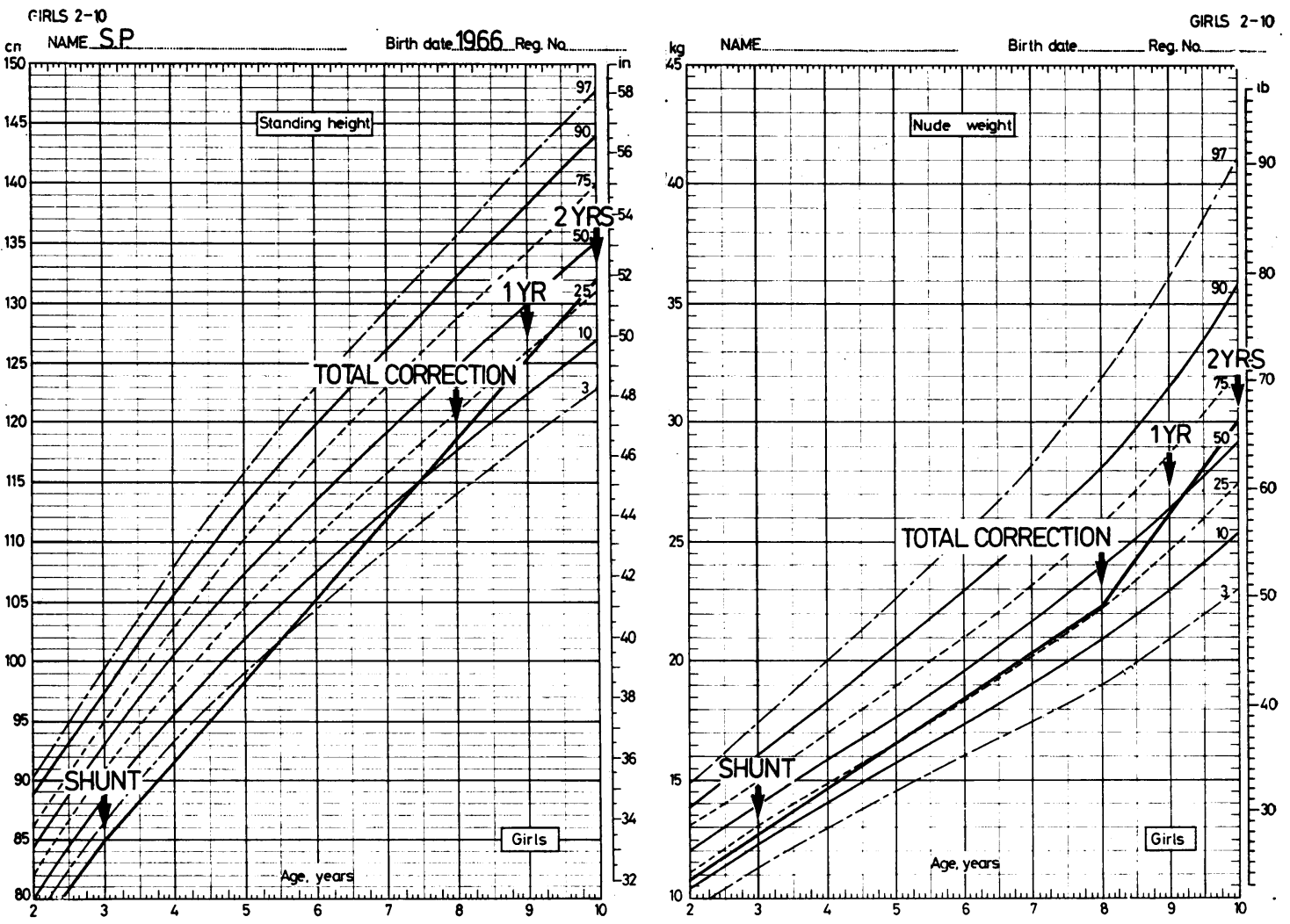

Fig. The growth chart of a patient who underwent a shunt procedure at 3 years of age and total correction at 8 years of age.

96th, 97th and above. In an attempt to define the aetiology of post-correction growth patterns, those patients who experienced accelerated development were compared with those patients who remained on or below the 3rd centile two years after total correction.

\section{Results}

The potential for physical development after a shunt procedure and total correction of Fallot's tetralogy is shown for an individual case in Fig. 1.

The mean birthweight of the 100 consecutive patients was $3220 \mathrm{~g} \pm 589 \mathrm{~g}(7 \cdot 1 \pm 1 \cdot 3 \mathrm{lb})$, a value just below the 50th centile for a sample of British children (Tanner et al., 1966).

Shunt procedures were performed before total correction in 45 children; 26 having a Waterston shunt and 19 a Blalock-Taussig. The mean age for the performance of shunts was $35 \cdot 6$ months. Tables

Table 1 Weight development before and after a shunt procedure

\begin{tabular}{|c|c|c|c|c|c|c|c|c|}
\hline & \multicolumn{8}{|c|}{ Pre-shunt centile groups } \\
\hline & $3 \downarrow$ & $3-9$ & $10-24$ & $25-49$ & $50-74$ & $75-89$ & $90-96$ & 97 and $\uparrow$ \\
\hline Total & $\begin{array}{l}18 \\
13\end{array}$ & 5 & 10 & 6 & 3 & 2 & 1 & \\
\hline $\begin{array}{l}3 \downarrow \\
3-9\end{array}$ & $\begin{array}{r}13 \\
3\end{array}$ & $\begin{array}{l}2 \\
2\end{array}$ & & 1 & & 1 & & \\
\hline $10-24$ & 2 & & $\begin{array}{l}2 \\
4\end{array}$ & 1 & & & & \\
\hline $\begin{array}{l}25-49 \\
50-74\end{array}$ & & 1 & 3 & 2 & & & & \\
\hline $75-89$ & & & 1 & 3 & 2 & 1 & 1 & \\
\hline $\begin{array}{l}90-90 \\
97 \text { and } \uparrow\end{array}$ & & & & & 1 & & & \\
\hline
\end{tabular}


Table 2 Height development before and after a shunt procedure

\begin{tabular}{|c|c|c|c|c|c|c|c|c|}
\hline & \multicolumn{8}{|c|}{ Pre-shunt centile groups } \\
\hline & $3 \downarrow$ & $3-9$ & $10-24$ & $25-49$ & $50-74$ & $75-89$ & $90-96$ & 97 and $\uparrow$ \\
\hline Total & 13 & 9 & 4 & 11 & 8 & & & \\
\hline $\begin{array}{l}3 \downarrow \\
3-9\end{array}$ & $\begin{array}{l}6 \\
5\end{array}$ & 4 & & & 1 & & & \\
\hline $10-24$ & 1 & 2 & & & & & & \\
\hline $25-49$ & & 2 & 2 & 6 & 1 & & & \\
\hline $\begin{array}{l}50-74 \\
75-89\end{array}$ & & & 2 & 5 & 3 & & & \\
\hline $\begin{array}{l}75-89 \\
90-96 \\
97 \text { and } \uparrow\end{array}$ & 1 & 1 & & & 3 & & & \\
\hline
\end{tabular}

Table 3 Weight development before and 2 years after total correction

\begin{tabular}{|c|c|c|c|c|c|c|c|c|}
\hline & \multicolumn{8}{|c|}{ Pre-total correction centile groups } \\
\hline & $3 \downarrow$ & $3-9$ & $10-24$ & $25-49$ & $50-74$ & $75-89$ & $90-96$ & 97 and $\uparrow$ \\
\hline Total & 20 & 15 & 11 & 11 & 10 & 3 & 2 & 1 \\
\hline $3 \downarrow$ & 8 & 1 & & & & & & \\
\hline $3-9$ & 7 & 7 & & 1 & & 1 & & \\
\hline $10-24$ & 4 & 5 & 2 & & & & & \\
\hline $25-49$ & 1 & 2 & 8 & 6 & & & & \\
\hline $50-74$ & & & 1 & 3 & 6 & & & \\
\hline 75-89 & & & & 1 & 3 & 1 & & \\
\hline $90-96$ & & & & & & 1 & 2 & 1 \\
\hline 97 and $\uparrow$ & & & & & 1 & & & \\
\hline
\end{tabular}

Table 4 Height development before and 2 years after total correction

\begin{tabular}{|c|c|c|c|c|c|c|c|c|}
\hline & \multicolumn{8}{|c|}{ Pre-total correction centile groups } \\
\hline & $3 \downarrow$ & $3-9$ & $10-24$ & $25-49$ & $50-74$ & $75-89$ & $90-96$ & 97 and $\uparrow$ \\
\hline Total & 6 & 17 & 12 & 17 & 12 & 7 & 2 & \\
\hline $3 \downarrow$ & 3 & 1 & & & & & & \\
\hline $3-9$ & 3 & 8 & 1 & & & & & \\
\hline $10-24$ & & 8 & 5 & 1 & & & & \\
\hline $25-49$ & & & 6 & 12 & & & & \\
\hline $50-74$ & & & & 4 & 8 & 2 & & \\
\hline $75-89$ & & & & & 3 & 4 & & \\
\hline $\begin{array}{l}90-96 \\
97 \text { and } \uparrow\end{array}$ & & & & & 1 & 1 & 2 & \\
\hline
\end{tabular}

1 and 2 are concerned only with those 45 patients who had undergone a shunt procedure. They compare the numbers in each centile group for height and weight immediately before the shunt procedure with those immediately before total correction. For weight, 14 patients showed accelerated postoperative gain, 24 remained on the same centile, and 7 suffered retardation in weight development. For height, 24 patients showed accelerated development, 19 progressed along the same centile, and 2 suffered retardation.

Postoperative deaths and the loss of 3 patients to follow-up reduced the number of patients available for study 2 years after total correction to 73 . In Tables 3 and 4 , the centile ratings for height and weight immediately before total correction are compared with those obtained two years after the procedure. For weight, 37 patients showed accelerated postoperative gain, 32 stayed on the same centile, and 4 suffered retardation. For height, 26 patients showed accelerated postoperative development, 42 developed along the same centile, and 5 suffered retardation.

To define the aetiological factors responsible for changes in growth pattern, patients who had experienced accelerated growth were compared with those who remained on or below the 3rd centile. Two years after total correction 23 patients had experienced accelerated development for both height and weight. Eleven patients remained on or below the 3rd centile for both height and weight. Table 5 shows that in terms of the age at shunting, the 
Table 5 Accelerated growth compared with retarded growth

\begin{tabular}{|c|c|c|c|c|}
\hline & & \multicolumn{3}{|c|}{ Two years after total correction } \\
\hline & & All patients & $\begin{array}{l}\text { Acceleration in height and } \\
\text { weight }\end{array}$ & $\begin{array}{l}\text { Retardation in height and } \\
\text { weight }\end{array}$ \\
\hline $\begin{array}{l}\text { Patients } \\
\text { Shunts }\end{array}$ & $\begin{array}{l}\text { Waterston } \\
\text { Blalock }\end{array}$ & $\begin{array}{l}73 \\
26 \\
19 \\
-\end{array}$ & $\begin{array}{l}23 \\
4(17 \cdot 4 \%) \\
5(21 \cdot 7 \%) \\
\end{array}$ & $\begin{array}{l}11 \\
5(45 \cdot 4 \%) \\
2(18 \cdot 2 \%) \\
-\end{array}$ \\
\hline $\begin{array}{l}\text { Mean age } \\
\text { Mean age } \\
\text { Oxygen s: } \\
\text { Patch rep } \\
\text { RV press? }\end{array}$ & $\begin{array}{l}\text { Total } \\
\text { at shunting (mth) } \\
\text { eat total correction (mth) } \\
\text { aturation immediately before total correction } \\
\text { air right ventriculotomy } \\
\text { ure greater than } \$ \mathrm{LV} \text { pressure }\end{array}$ & $\begin{array}{l}45(61 \cdot 6 \%) \\
35 \cdot 6 \pm 22 \cdot 8 \\
83 \cdot 3 \pm 43 \cdot 5 \\
81 \cdot 6 \pm 10 \cdot 5 \\
-\end{array}$ & $\begin{array}{l}9(39 \cdot 1 \%) \\
45 \cdot 7 \pm 27 \cdot 5 \\
92 \cdot 2 \pm 33 \cdot 7 \\
80 \cdot 1 \pm 13 \cdot 2 \\
6(26 \cdot 1 \%) \\
2(8 \cdot 7 \%)\end{array}$ & $\begin{array}{l}7(63 \cdot 6 \%) \\
32 \cdot 9 \pm 19 \cdot 9 \\
93 \cdot 1 \pm 46 \cdot 3 \\
82 \cdot 8 \pm 10 \cdot 8 \\
3(27 \cdot 2 \%) \\
1(9 \%)\end{array}$ \\
\hline
\end{tabular}

\pm Standard deviation.

oxygen saturation immediately before total correction, the age at total correction, the number of ventriculotomy patch repairs, and the post-correction ventricular pressure ratios, no difference could be detected between those 23 patients who had shown accelerated height and weight development and those 11 patients who had remained small. Shunts were performed in 39.1 per cent of the accelerated group and in 63.6 per cent of the retarded group. Waterston shunts were performed in 45.4 per cent of the retarded group and in 17.4 per cent of the accelerated growth group.

\section{Discussion}

The mean birthweight of our children was just below the 50th centile value calculated by Tanner $e t$ al. (1966) from a sample of British children. Allowing for regional variations in stature and the inclusion of some children from overseas, the small variation from the 50th centile in our series is of little significance. This observation agrees with that of Feldt et al. (1969) whoin an analysis of birthweights measured in groups of children with various cardiac anomalies were unable to show any significant difference between each group and a group of normal children. Since the onset of this series 11 years ago, advances in technology and technique have produced a changing attitude towards shunting procedures. Early in our series many of the shunts were performed in older children with a view to delaying total correction until further growth had taken place. In recent years more of our patients have undergone total corrections as primary procedures at much earlier ages. For those children who underwent a shunt procedure, a considerable degree of retardation in physical development had taken place by the time of operation; approximately half of the patients were below the 10th centile for height and weight at the time of shunting. Patients who did not require a shunt procedure were less severely retarded. After the shunt procedures, more than half the patients showed accelerated height development but only a third showed accelerated weight gain. In contrast, Starr et al. (1973) who advocate early total correction, failed to show significant growth acceleration after 16 shunt procedures. This discrepancy with our results could be accounted for by the difference in patient selection. Their series consisted of very severely hypoxic infants, all below the age of 2 years who were considered to be extremely 'bad risk' patients for total correction. Many of the shunts in our series were performed on older children with milder lesions.

After total correction there was obvious acceleration in both height and weight development. Two years after total correction, a half of the patients had crossed into a higher centile group for weight and a third experienced accelerated height development. Most of the cases of accelerated growth were found in the lower centile groups. Those patients above the 50th centile preoperatively showed little change in growth pattern postoperatively.

By comparing those patients who had accelerated development with those who remained small after total correction, several observations can be made. Fewer of the patients with accelerated development underwent shunt operations. A considerably higher proportion of the retarded patients underwent a Waterston shunt. We cannot prove, but suspect that this reflects a higher incidence of severe anatomical change in the retarded group. In addition, Waterston shunts are followed by a high incidence of transient pulmonary congestion and congestive cardiac failure. Our paper supports the view of Robinson and Bayer (1969) that generalised tissue hypoxia can produce retardation in growth. However, our results failed to prove a linear relation between the degree of retardation and the extent of arterial desaturation. Many of the retarded patients had comparatively 
high $\mathrm{PaO}_{2}$ values. The frequency of right ventriculotomy patch repairs was similar for the accelerated and retarded groups as was the incidence of high right ventricular pressures after correction. Thus in terms of the above values, we have been unable to show any gross differences between patients who show accelerated development and those who show retarded growth. Assuming that there must be some physiological reasons for the differences in growth, various possibilities remain. For example, subtle changes in right ventricular performance related to the extent of the ventriculotomy or disturbance in right ventricular coronary flow. Naeye (1965) comparing two groups of children, one with congenital cyanotic heart disease and the other with alimentary malnutrition, suggested that irreversible changes in the brain could influence subsequent development even if an adequate operative correction was performed.

Although our results have been encouraging, the patients were collected over a long period which has seen changes in the operative approach to Fallot's tetralogy. It is with interest that we await results of treatment by early total correction.

\section{References}

Adams, F. A., and Forsyth, W. B. (1951). Effect of surgery on the growth of patients with patent ductus arteriosus. Fournal of Pediatrics, 39, 330-336.

Blalock, A., and Taussig, H. B. (1945). The surgical treatment of malformations of the heart in which there is pulmonary stenosis or pulmonary atresia. Fournal of the American Medical Association, 128, 189-202.

Fallot, A. (1888). Contribution a l'Anatomie Pathologique de la Maladie Bleue (Cyanose Cardiaque). Barlatier-Feissat, Marseilles.

Feldt, R. H., Strickler, B. G., and Weidman, W. H. (1969). Growth of children with congenital heart disease. American fournal of Diseases of Children, 117, 573-579.

Mazur, J. A. (1959). Growth failure associated with congenital heart disease. Clinical Proceedings of the Children's Hospital, 15, 87-92.

Mehrizi, A., and Drash, A. (1962). Growth disturbance in congenital heart disease. Fournal of Pediatrics, 61, 418-429.

Naeye, R. L. (1965). Organ and cellular development in congenital heart disease and in alimentary malnutrition. Fournal of Pediatrics, 67, 447-458.

Naeye, R. L. (1967). Anatomical features of growth failure in congenital heart disease. Pediatrics, 39, 433-440.

Robinson, S. J., and Bayer, L. M. (1969). Growth history of children with congenital heart defects. I. Effect of operative intervention. Child Development, 40, 315-346.

Schlange, H. (1962). Physical and mental development in children with congenital heart disease and vascular abnormalities. Archiv für Kinderheilkunde, Suppl. 47, 1-61.

Starr, A., Bonchek, L. I., and Sunderland, C. O. (1973). Total correction of tetralogy of Fallot in infancy. Fournal of Thoracic and Cardiovascular Surgery, 66, 45-57.

Tanner, J. M., Whitehouse, R. H., and Takaishi, M. (1966). Standards from birth to maturity for height, weight, height velocity and weight velocity: British children, 1965. Part II. Archives of Disease in Childhood, 41, 613-635.

Waterston, D. J. (1962). Treatment of Fallots tetralogy in infants under the age of one year. (In Czech.) Razhledy v chirurgii, 41, 181-183.

Requests for reprints to R. E. Page, Esq., F.R.C.S., Department of Plastic Surgery, St. James's Hospital, Beckett Street, Leeds 9. 